\title{
Capacidade de combinação em milho para resistência a Cercospora zeae-maydis ${ }^{1}$
}

\author{
Combining ability in maize for resistance to the Cercospora zeae-maydis
}

\author{
Marcio José Engelsing ${ }^{2}$, Diane Simon Rozzetto ${ }^{2}$, Jefferson Luís Meirelles Coimbra ${ }^{2 *}$, Claitson Gustavo Zanin² e \\ Altamir Frederico Guidolin²
}

\begin{abstract}
Resumo - A resistência obtida pelo componente genético é um dos métodos mais eficientes de controle das doenças foliares da cultura do milho. Para avaliar a capacidade geral de combinação (CGC), capacidade específica de combinação (CEC), recíprocos, efeito materno e não-materno para resistência a Cercospora zeae-maydis, cinco linhagens (A, B, $\mathrm{C}, \mathrm{D}$ e E) foram cruzadas e os vinte híbridos obtidos foram utilizados em experimentos conduzidos em três ambientes. Foram avaliados a severidade da cercosporiose (CP) no estádio fenológico R5 e o rendimento de grãos (RG) na colheita. A análise dialélica demonstrou que ocorreu interação significativa $(\mathrm{P}<0,05)$ híbridos versus locais para as variáveis CP e RG. D e E foram os melhores genitores para a para a variável cercosporiose de acordo com a CGC. Na média dos locais as melhores combinações híbridas, conforme a $\mathrm{CEC}$ foram $\mathrm{AxD}, \mathrm{BxE}, \mathrm{AxE}$ e $\mathrm{BxC}$, com estimativa de aumento nos rendimentos de grãos, devendo ser recomendado a continuação destes híbridos no programa de melhoramento da empresa.
\end{abstract}

Palavras-chave - Zea mays L. Análise dialélica. Cercosporiose. Rendimento.

\begin{abstract}
The resistance due to genetic component is the most efficient method to control maize leaf diseases. The general combining ability (GCA), the specific combining ability (SCA), the reciprocal, the maternal and the notmaternal were evaluated for resistance to the Cercospora zeae-maydis at twenty hybrids. The hybrids were originated from crosses of five parents (A, B, C, D and E). The experiment was conducted in three environments. The resistance to Cercospora zeae-maydis was evaluated using grain yield (RG) in the harvest and the severity of Gray leaf spot (GLS) at physiological maturation, using the scale proposed by Agroceres (1996). The dialelic analysis demonstrated a significant interaction $(\mathrm{P}<0,05)$ between hybrids versus places for GLS and RG. For the variable GLS, the GCA demonstrated that the best genitors had been $\mathrm{D}$ and $\mathrm{E}$, different of that observed in grain yield (A and B). When considering SCA, the best hybrids combinations at the average places were $\mathrm{AxD}, \mathrm{BxE}, \mathrm{AxE}$ and $\mathrm{BxC}$, and should be recommended the maintenance of these hybrids in the company breeding program.
\end{abstract}

Key words - Zea mays L. Diallel analysis. Gray leaf Spot. Yield.

\footnotetext{
* Autor para correspondência

${ }^{1}$ Recebido para publicação em 02/09/2009; aprovado em 21/01/2011

Parte da Dissertação do primeiro autor apresentado no Programa de Pós-Graduação em Produção vegetal da UDESC

${ }^{2}$ Universidade do Estado de Santa Catarina, Departamento de Agronomia, Programa de Pós-Graduação em Ciências Agrárias, Instituto de Melhoramento

e Genética Molecular da UDESC (IMEGEM). Av. Luiz de Camões nº 2090, Conta Dinheiro, Lages-SC, Brasil, 88.520-000, a2jlm@cav.udesc.br
} 


\section{Introdução}

A importância da cultura do milho (Zea mays L.) caracteriza-se por suas diversas formas de utilização (FERREIRA, 2007). Sua área plantada e produtividade vêm aumentando nas últimas décadas, caracterizando papel importante no agronegócio brasileiro (MONTEZANO et al., 2008). Contudo, o dano causado por doenças na cultura vem aumentando no Brasil (REIS et al., 2004). Entre estas, a cercosporiose, causada pelo fungo Cercospora zeae-maydis Tehon \& E. Y. Daniels, é uma das principais que causam reduções significativas no rendimento da cultura (PIORIBEIRO et al., 2005; REIS et al., 2004). Brunelli (2004), estudando isolados deste fungo coletados em campos de produção de milho das regiões Centro e Sul do Brasil, observou a existência, de forma generalizada, de dois grupos genéticos do patógeno, grupos I e II. Estes grupos apresentam alta similaridade genética, sempre maior que $90 \%$, o que pode ser decorrência da baixa capacidade de recombinação ou mutação desses isolados (BRITO et al., 2007). O patógeno coloniza grande parte do tecido foliar, diminuindo sua área, levando a senescência precoce e diminuindo a produtividade de grãos. Munkvold et al. (2001) relatam prejuízos de U\$ 100 milhões no estado de Iowa e 11 a $69 \%$ de redução no rendimento de grãos nos USA e África do Sul.

O milho é cultivado principalmente em pequenas propriedades em Santa Catarina, Rio Grande do Sul e Minas Gerais. Segundo Cardoso et al. (2007), a utilização de variedades melhoradas pode proporcionar melhorias nos sistemas de produção. Em um programa de melhoramento visando a resistência genética a doenças, devem ser determinados os parâmetros genéticos que governam esta resistência. Para se obter sucesso em programas de melhoramento, é necessário dispor de alta variabilidade, bem como a escolha de populações com potencial considerável (KOUTSIKA-SOTIRIOU; KARAGOUNIS, 2005; TROYER, 1999).

Estudos têm concluído que a ação gênica aditiva tem predominância sobre a não-aditiva (CROMLEY et al., 2002; MENKIR; AYODELE, 2005) e em vários casos a capacidade geral de combinação (CGC) foi responsável por 100\% da resistência a CP (THOMPSON et al., 1987; ULRICH et al., 1990). A CGC permite determinar a contribuição de cada genitor e identificar as melhores combinações híbridas pela CEC. Uma das primeiras decisões a serem tomadas pelo melhorista deve ser a escolha dos genitores. O método de análise dialélica é uma estratégia que permite a identificação precoce de híbridos capazes de produzir uma progênie superior (BARBIERI et al., 2001).

Existem vários métodos empregados para a análise e interpretação de cruzamento dialélico (CRUZ; REGAZZI, 1997). Com base nas diferenças entre os métodos e em função dos objetivos a serem Alcançados, cada pesquisador escolhe o melhor método a ser utilizado. Um exemplo, dentre os principais métodos, pode ser destacado o de Griffing (1956) que fornece dados sobre a capacidade geral e específica de combinação dos genitores em cruzamentos artificiais. Neste método as somas dos quadrados de tratamentos são desdobradas em efeito da CGC, CEC e em efeitos recíprocos.

A correta interpretação da CGC e da CEC, relacionada com os efeitos aditivos e não aditivos, pode viabilizar o sucesso do melhoramento genético.

Este estudo teve como objetivo avaliar a capacidade geral e específica de combinação (CGC) e (CEC), através do cruzamento dialélico e seus recíprocos, para fornecer informações genéticas sobre a sanidade e sua interferência no componente de rendimento de grãos na cultura de milho.

\section{Material e métodos}

Germoplasma e obtenção de híbridos: Para a análise dialélica, cinco linhagens, denominadas genitores A, B, C, D e E, foram cruzadas entre si na safra de verão de 2006/07. A partir destes cruzamentos obtiveram-se vinte híbridos simples, sendo 10 híbridos $\mathrm{F}_{1}$ 's e 10 híbridos $\mathrm{F}_{1}$ 's recíprocos (TAB.1).

Tabela 1 - Esquema ilustrativo do dialelo com cinco linhagens. Lages/SC 2009

\begin{tabular}{cccccc}
\hline GENITORES & $\mathrm{A}$ & $\mathrm{B}$ & $\mathrm{C}$ & $\mathrm{D}$ & $\mathrm{E}$ \\
\hline $\mathrm{A}$ & & $\mathrm{AB}$ & $\mathrm{AC}$ & $\mathrm{AD}$ & $\mathrm{AE}$ \\
$\mathrm{B}$ & $\mathrm{BA}$ & & $\mathrm{BC}$ & $\mathrm{BD}$ & $\mathrm{BE}$ \\
$\mathrm{C}$ & $\mathrm{CA}$ & $\mathrm{CB}$ & & $\mathrm{CD}$ & $\mathrm{CE}$ \\
$\mathrm{D}$ & $\mathrm{DA}$ & $\mathrm{DB}$ & $\mathrm{DC}$ & & $\mathrm{DE}$ \\
$\mathrm{E}$ & $\mathrm{EA}$ & $\mathrm{EB}$ & $\mathrm{EC}$ & $\mathrm{ED}$ & \\
\hline
\end{tabular}

A seleção dos genitores avaliados foi em função do conhecimento prévio do nível de resistência a cercosporiose e de seu potencial produtivo. As linhagens foram obtidas por meio de autofecundações $\left(\mathrm{S}_{7}\right)$.

O campo de cruzamento para obtenção das sementes foi conduzido na estação experimental da empresa Agroeste Sementes S.A, no município de Campo Verde/MT, nos meses de março a julho de 2007. Foram semeados 15 metros lineares de cada genitor, obedecendo ao espaçamento de 0,65 metros entre linhas e 4 sementes por metro linear, totalizando assim uma densidade de 60.000 plantas ha ${ }^{-1}$. O mesmo procedimento foi repetido numa segunda época, 15 dias após a primeira semeadura. Os genitores A, C, D e E foram classificadas como moderadamente resistentes e B, como moderadamente suscetível, de acordo com a severidade de cercosporiose (TAB.2). 
Tabela 2 - Descrição dos genitores utilizados. Lages/SC, 2009

\begin{tabular}{clllc}
\hline Linhagem & Ciclo & Grão & Reação para cercosporiose & Estatura \\
\hline "A" & Precoce & Semi-dentado & Moderadamente Resistente & Alta \\
"B" & Precoce & Dentado & Moderadamente Suscetível & Média \\
"C" & Precoce & Semi-dentado & Moderadamente Resistente & Média \\
"D" & Precoce & Semi-dentado & Moderadamente Resistente & Baixa \\
"E" & Precoce & Semi-dentado & Moderadamente Resistente & Média \\
\hline
\end{tabular}

No período de florescimento foram realizados todos os cruzamentos possíveis entre os genitores, onde se obteve, após maturação, os híbridos $\mathrm{F}_{1}$ `s e $\mathrm{F}_{1}$ `s recíprocos.

Delineamento experimental: Foi utilizado o delineamento em blocos casualizados, com três repetições, envolvendo os tratamentos com híbridos e recíprocos (TAB.1) cultivados em três locais: Água Doce/SC, Iraí de Minas/MG e Chapadão do Céu/GO.

As parcelas experimentais foram constituídas de quatro fileiras (linhas) de cinco metros de comprimento, sendo as duas fileiras centrais consideradas como úteis. Utilizou-se o espaçamento de $0,65 \mathrm{~m}$ entre fileiras, com densidade de 4 plantas por metro linear, sendo a população de plantas final estabelecida em 60.000 plantas ha $^{-1}$, nos três locais, após realização do desbaste. Em todos os locais ocorreu a semeadura das áreas com sistema de plantio direto em monocultura de milho. As práticas culturais foram realizadas de acordo com as recomendações da Reunião técnica anual de pesquisa de milho e sorgo (2005).

\section{Avaliações dos $F_{1}$ `s e $F_{1}$ 's recíprocos:}

Experimento 1: Água Doce/SC: O ensaio foi implantado em 26/09/2007, área situada a 1.260 metros de altitude, a $26^{\circ} 47^{\prime} 8$ " de latitude sul e 51 $34^{\prime} 32^{\prime \prime}$ de longitude oeste, solo tipo Nitossolo Bruno. O clima da região é considerado mesotérmico, classificado segundo Köppen-Geiger como $\mathrm{Cfb}$, com verão brando e chuvas bem distribuídas durante o ano, com média anual em torno de $1.500 \mathrm{~mm}$. Apresenta ainda temperatura média anual próxima de $15^{\circ} \mathrm{C}$.

Experimento 2: Iraí de Minas/MG: A semeadura do segundo experimento foi realizado em 27/10/2007. A área apresenta $1.015 \mathrm{~m}$ de altitude, com $18^{\circ} 58^{\prime} 17^{\prime \prime} \mathrm{de}$ latitude sul e 47³3'52" de longitude oeste, solo tipo Latossolo Vermelho. O clima da região é considerado tropical de altitude, Cwa de acordo com a classificação de Köppen-Geiger. Apresenta uma temperatura média anual em torno de 19 a $21{ }^{\circ} \mathrm{C}$, com precipitações pluviométricas anuais em torno de $1.500 \mathrm{~mm}$, concentrando as chuvas no período de setembro a maio.

Experimento 3: Chapadão do Céu/GO: O último experimento foi conduzido numa área com altitude de 815 metros, a $18^{\circ} 26^{\prime} 39^{\prime \prime}$ de latitude sul e $52^{\circ} 31^{\prime} 51^{\prime \prime}$ de longitude oeste, solo tipo Latossolo Vermelho amarelo. O experimento foi implantado na data de 21/11/2007. Köppen-Geiger classifica a região como Aw, tropical úmido com chuvas no verão, aproximadamente 2.000 $\mathrm{mm}$, e seca no inverno. Apresenta uma temperatura média anual variando entre 21 e $23{ }^{\circ} \mathrm{C}$.

Avaliações de severidade da cercosporiose e rendimento de grãos: Para avaliação da doença, foi utilizada a escala diagramática de severidade, obtidas com o auxílio da escala proposta pela Agroceres (1996). As notas desta escala variam de 1 a 9 , sendo que $1=0 \%$ de doença, $2=0,5 \%, 3=10 \%, 4=30 \%, 5=50 \%, 6=70 \%$, $7=80 \%, 8=90 \%$ e $9=100 \%$ de área da folha lesionada, considerando a severidade média da doença em todas as plantas da parcela. A avaliação foi realizada no estádio fenológico R5, característica de grão farináceo duro, sendo realizadas pelo mesmo avaliador nos diferentes locais.

Para a variável rendimento de grãos, foi realizada a colheita e a debulha das espigas da área útil de cada parcela e pesados os grãos e ajustado seu peso para umidade de $13 \%$. Com o peso da parcela foi estimado rendimento de grãos em $\mathrm{kg} \mathrm{ha}^{-1}$.

Análises estatísticas: Foi realizada a análise estatística conjunta dos três experimentos através do cruzamento dialélico proposto por Griffing (1956), conforme o método 3 (híbridos e recíprocos, exceto os genitores), modelo 2 (modelo de efeitos fixos), para severidade da cercosporiose, com dados transformados por ${ }^{2} \sqrt{ }(x+3 / 8)$ e rendimento de grãos da cultura do milho. Os parâmetros genéticos estimados foram: 1) capacidade geral de combinação (CGC); 2) capacidade específica de combinação (CEC); 3) efeito materno (efeito recíproco geral); 4) não-materno (efeito recíproco específico). 


\section{Resultados e discussão}

Os resultados obtidos por meio da análise de variância conjunta (TAB. 3) evidenciam um efeito significativo $(\mathrm{P}<0,05)$ para a interação híbridos versus locais, tanto para CP quanto para RG. Desta maneira, foi desdobrada a soma dos quadrados de tratamentos em CGC e CEC, recíprocos, efeito materno e nãomaterno, conforme o método 3, modelo 2 de Griffing (1956), dentro de local.

Foram constatados efeitos significativos $(\mathrm{P}<0,05)$ para híbridos e capacidade geral de combinação (CGC), para os três ambientes e as duas variáveis analisadas, cercosporiose e rendimento de grãos (TAB. 4).

A capacidade específica de combinação (CEC) apresentou significativa variação $(\mathrm{P}<0,05)$ para as duas variáveis e locais, exceto para o local Iraí de
Minas. Essa significância para ambas as capacidades de combinação concordam com os resultados obtidos por Parentoni et al. (1991) que ressaltam a existência de variabilidade tanto para efeitos gênicos aditivos (CGC) como não-aditivos (CEC).

O efeito recíproco e os efeitos materno e nãomaterno não apresentaram significância. Derera et al. (2008), comparando grupos de genitores resistentes versus suscetíveis à cercosporiose, não encontraram evidências sobre o efeito materno. Neste trabalho não se encontrou significância para o efeito materno, pois provavelmente não ocorreu uma influência significativa dos genes citoplasmáticos. Silva et al. (2001) e Pegoraro et al. (2002), avaliando ferrugem polissora (Puccinia polysora) e mancha branca (Phaeosphaeria maydis), respectivamente, na cultura do milho, também não relataram contribuição do efeito materno.

Tabela 3 - Análise conjunta para cercosporiose (CP) e rendimento de grãos (RG), nos ensaios conduzidos em três locais. Lages/SC, 2009

\begin{tabular}{lccc}
\hline \multirow{2}{*}{ FV } & GL & \multicolumn{2}{c}{ Quadrado Médio } \\
\cline { 3 - 4 } & & CP & RG \\
\hline Repetições & 6 & 0,64 & 506,12 \\
Locais & 2 & $49,24^{*}$ & $49423,28^{*}$ \\
Híbridos & 19 & $6,01^{*}$ & $2238,94^{*}$ \\
Híbridos x locais & 38 & $1,12^{*}$ & $576,38^{*}$ \\
Resíduo & 115 & 0,33 & 329,75 \\
\hline
\end{tabular}

* significativo a $5 \%$ pelo teste $F$

Tabela 4 - Quadrados médios da capacidade geral de combinação (CGC), capacidade específica de combinação (CEC), recíprocos, efeito materno e não-materno, para cercosporiose (CP) e rendimento de grãos (RG) para os vinte híbridos avaliados em três locais de cultivo. Lages/SC, 2009

\begin{tabular}{lccccccc}
\hline \multirow{2}{*}{ FV } & GL & \multicolumn{9}{c}{ Locais } \\
\cline { 3 - 8 } & & \multicolumn{2}{c}{ Água Doce } & \multicolumn{2}{c}{ Iraí de Minas } & \multicolumn{2}{c}{ Chapadão do Céu } \\
\cline { 2 - 7 } & & CP & RG & CP & RG & CP & RG \\
\hline Repetições & 2 & 0,45 & 1110,10 & $1,12^{*}$ & 325,35 & 0,35 & 82,92 \\
Genótipos & 19 & $4,78^{*}$ & $1754,20^{*}$ & $1,30^{*}$ & $1213,99^{*}$ & $2,16^{*}$ & $423,50^{*}$ \\
CGC & 4 & $19,62^{*}$ & $4999,18^{*}$ & $5,03^{*}$ & $4497,34^{*}$ & $8,46^{*}$ & $1139,55^{*}$ \\
CEC & 5 & $1,57^{*}$ & $1790,70^{*}$ & 0,31 & 336,36 & $1,13^{*}$ & $376,52^{*}$ \\
Recíprocos & 10 & 0,45 & 437,97 & 0,30 & 339,47 & 0,15 & 160,57 \\
Materno & 4 & 0,67 & 499,67 & 0,12 & 137,06 & 0,02 & 206,31 \\
Não-materno & 6 & 0,31 & 396,83 & 0,42 & 474,42 & 0,24 & 130,07 \\
Erro & 38 & 0,45 & 617,67 & 0,33 & 225,85 & 0,21 & 145,72 \\
\hline \multicolumn{1}{c}{ CV (\%) } & \multicolumn{10}{c}{16,98} & 13,18 & 24,51 & 11,01 & 11,89 & 8,52 \\
\hline
\end{tabular}


Os cruzamentos dialélicos proposto por Griffing (1956) são baseados nos conceitos da capacidade geral de combinação e específica estabelecida por Sprague e Tatum (1942). Estes autores definiram a CGC como o desempenho médio de uma linhagem em combinações híbridas e CEC como o desempenho da combinação híbrida que são melhores ou inferiores comparadas ao desempenho médio das linhagens envolvidas. Também, interpretaram a CGC como uma indicação dos genes que têm efeitos aditivos significativos e CEC como indícios dos genes de dominância e efeitos epistáticos.

A significância para a CGC e a CEC indica a existência de variabilidade entre os efeitos da CGC associados a efeitos gênicos aditivos, e entre os efeitos da CEC associados aos não-aditivos. Os efeitos de CGC foram mais importantes que os de CEC nesse conjunto de genitores, julgando pelos valores de seus quadrados médios. Fato importante a ser observado está relacionado com a magnitude dos quadrados médios de CGC e CEC, evidenciando que para os caracteres analisados a CGC foi superior à CEC, enfatizando, assim, a grande contribuição da ação gênica aditiva no controle dos caracteres estudados. Estes resultados concordam com os encontrados por Derera et al. (2008), que concluíram que para a cercosporiose e rendimento de grãos a soma de quadrados da CGC foi superior à da CEC destes caracteres.

Efeitos genéticos aditivos são mais importantes como fonte de variação para resistência a cercosporiose e rendimento de grãos (TAB. 4). Outros autores também têm relatado predominância da $\mathrm{CGC}$ em relação à $\mathrm{CEC}$ para rendimento de grãos de milho (AGUIAR et al., 2003; BECK et al., 1990; GAMA et al., 1995).

A variabilidade da CGC permite inferir que os genitores contribuíram diferentemente nos cruzamentos envolvidos. Silva et al. (2001), estudando a resistência à Puccinia polysora em milho, definiram CGC sendo mais importante que a CEC, o que confirma os dados encontrados e sugere que os efeitos gênicos aditivos provavelmente sejam mais importantes como fonte de variação também para Cercospora zeae-maydis.

De acordo com Miranda et al. (1998), os genitores que apresentarem as mais elevadas CGC devem ser preferidos para fazerem parte das combinações híbridas, favorecendo a seleção de linhagens homozigotas em espécies autógamas. Para Cruz e Regazzi (1997), valores elevados para CGC, positivos ou negativos, revelam que o genitor é muito superior ou inferior, respectivamente, aos demais genitores do dialélico.

$\mathrm{Na}$ Tabela 5 estão inseridas as médias para o caráter $\mathrm{CP}$, onde pode ser observado que para o ambiente Água Doce, quando o genitor D é cruzado com os demais genitores, todas as combinações híbridas ficam com notas de severidade abaixo da média geral, exceto quando cruzado com o genitor A. Em Iraí de Minas, somente os híbridos $\mathrm{CxD}, \mathrm{CxE}, \mathrm{DxB}, \mathrm{DxC}$ e ExD obtiveram severidade inferior a média geral. A média dos híbridos $\mathrm{CxD}, \mathrm{CxE}, \mathrm{DxE}$ e seus recíprocos foram inferiores à média geral na localidade de Chapadão do Céu. Estes dados sugerem que o genitor D, de uma maneira geral, quando combinado com os demais genitores constituem progênies superiores para o caráter avaliado, exceto quando combinado com o genitor A. Desta forma pode ser percebido que o genitor A reduz a resistência das plantas à doença, na média dos três locais. Isto significa dizer que em todos os cruzamentos avaliados onde o genitor D participa o híbrido formado possui características de resistência a cercosporiose, exceto para $\mathrm{BxD}$ e DxE em Iraí de Minas e BxD e DxB em Chapadão do Céu que obtiveram valores acima da média geral (TAB. 5). $\mathrm{O}$ fato de resistência à doença demonstrada pelas estimativas dos efeitos da CGC para o genitor D é relevante em termos de programas de melhoramento; porém, deve ser salientado que esta característica deve estar aliada a seleção de progênies superiores também para o caráter RG.

$\mathrm{Na}$ Tabela 6 podem ser visualizadas as médias de rendimento de grãos (RG) dos genótipos e a média geral de cada local. As combinações híbridas $\mathrm{CxD}, \mathrm{CxE}$, DxE e seus respectivos recíprocos aparecem nos três ambientes com rendimento de grãos inferiores à média geral de cada local. Ainda em Água Doce, os híbridos AxE, ExA, AxC e BxC também obtiveram médias abaixo da média geral. Em Iraí de Minas, as médias de rendimento de grãos dos híbridos $\mathrm{DxA}, \mathrm{BxD}$ e seu recíproco foram inferiores à média geral deste local. Já na localidade de Chapadão do Céu, além dos genótipos citados anteriormente, $\mathrm{BxE}, \mathrm{AxC}$ e $\mathrm{CxA}$ mostraram-se inferiores à média geral. Estes resultados indicam que, em geral, as estimativas dos efeitos da CGC nos genitores $\mathrm{C}, \mathrm{D}$ e $\mathrm{E}$, quando utilizados em cruzamentos, poderão implicar na redução do caráter $R G$, fato altamente indesejado para o melhoramento da cultura do milho.

As combinações híbridas $\mathrm{CxD}, \mathrm{CxE}, \mathrm{DxE}$ e seus respectivos recíprocos aparecem nos três ambientes com rendimento de grãos inferiores à média geral de cada local. Ainda em Água Doce, os híbridos AxE, ExA, $\mathrm{AxC}$ e BxC também obtiveram médias abaixo da média geral. Em Iraí de Minas, as médias de rendimento de grãos dos híbridos $\mathrm{DxA}, \mathrm{BxD}$ e seu recíproco foram inferiores à média geral deste local. Já na localidade de Chapadão do Céu, além dos genótipos citados anteriormente, $\mathrm{BxE}, \mathrm{AxC}$ e CxA mostraram-se inferiores à média geral. Estes resultados indicam que, em geral, as estimativas dos efeitos da CGC nos genitores $\mathrm{C}, \mathrm{D}$ e $\mathrm{E}$, quando utilizados em cruzamentos, poderão implicar na redução do caráter $\mathrm{RG}$, fato altamente indesejado para o melhoramento da cultura do milho. 
Tabela 5 - Médias das reações a Cercorpora zeae-maydis, avaliadas conforme escala de severidade da doença (AGROCERES, 1996), dos cinco genitores e seus recíprocos em três ambientes. Lages/SC, 2009

\begin{tabular}{|c|c|c|c|c|c|}
\hline & & & líbrido & & \\
\hline LOCAIS & $\mathrm{A}$ & $\mathrm{B}$ & $\mathrm{C}$ & $\mathrm{D}$ & $\mathrm{E}$ \\
\hline \multicolumn{6}{|c|}{ Água Doce } \\
\hline $\mathrm{A}$ & - & 5,33 & 5,00 & 4,33 & 4,67 \\
\hline B & 5,33 & - & 4,33 & 3,00 & 5,00 \\
\hline $\mathrm{C}$ & 5,33 & 3,67 & - & 2,33 & 5,00 \\
\hline D & 4,00 & 2,00 & 2,00 & - & 2,00 \\
\hline E & 5,00 & 4,67 & 4,00 & 2,00 & - \\
\hline Média & 4,91 & 3,92 & $\overline{3,83}$ & 2,91 & 4,17 \\
\hline Média geral & & & 3,95 & & \\
\hline \multicolumn{6}{|c|}{ Iraí de Minas } \\
\hline A & - & 4,00 & 2,67 & 2,33 & 2,67 \\
\hline B & 3,33 & - & 2,33 & 2,00 & 2,33 \\
\hline $\mathrm{C}$ & 2,67 & 3,00 & - & 1,67 & 1,67 \\
\hline $\mathrm{D}$ & 2,33 & 1,67 & 1,33 & - & 2,00 \\
\hline E & 2,67 & 2,33 & 2,33 & 1,33 & - \\
\hline Média & 2,75 & 2,75 & 2,16 & 1,83 & 2,17 \\
\hline Média geral & & & 1,90 & & \\
\hline \multicolumn{6}{|c|}{ Chapadão do Céu } \\
\hline A & - & 4,33 & 5,33 & 4,00 & 4,00 \\
\hline B & 5,00 & - & 4,00 & 4,33 & 3,67 \\
\hline $\mathrm{C}$ & 5,00 & 4,33 & - & 3,33 & 3,33 \\
\hline $\mathrm{D}$ & 4,00 & 4,00 & 3,33 & - & 2,00 \\
\hline $\mathrm{E}$ & 3,67 & 4,00 & 3,33 & 2,00 & - \\
\hline Média & 4,42 & 4,16 & 4,00 & 3,41 & 3,25 \\
\hline Média geral & & & 3,85 & & \\
\hline
\end{tabular}

Na Tabela 7, estão demonstrados os cinco genitores avaliados, por meio da estimativa dos efeitos da CGC.

Os genitores $\mathrm{A}$ e $\mathrm{B}$ foram os que mais contribuíram para o aumento do rendimento de grãos. $\mathrm{O}$ genitor A obteve aumento de $964 \mathrm{~kg} \mathrm{ha}^{-1} \mathrm{em}$ Água Doce e $798 \mathrm{~kg} \mathrm{ha}^{-1}$, na localidade de Iraí de Minas. Por outro lado o genitor $\mathrm{B}$ também alcançou aumento no rendimento de grãos nos três ambientes, $1.117 \mathrm{~kg} \mathrm{ha}^{-1}, 874 \mathrm{~kg} \mathrm{ha}^{-1} \mathrm{e}$ $637 \mathrm{~kg} \mathrm{ha}^{-1}$, em Água Doce, Iraí de Minas e Chapadão do Céu, respectivamente. Os genitores A e B; mesmo com o aumento da severidade da doença (TAB. 7), quando os mesmos aumentaram, respectivamente, as notas da doença em 1,23 e 0,29, em Água Doce; 0,67 e 0,39, em Iraí de Minas e 0,76 e 0,48 , em Chapadão do Céu; alcançaram rendimento de grãos superiores aos demais genitores em todos os ambientes. $\mathrm{O}$ genitor $\mathrm{C}$ apresentou resultados de CP e RG estáveis, exceto em Chapadão do Céu onde se verificou aumento de 0,20 na nota de severidade de cercosporiose. Esta característica foi descrita por Cruz e Regazzi (1997), para os quais estimativas baixas para a CGC de certo genitor indicam que o mesmo não difere da média geral do dialélico.

Já para o caráter $\mathrm{CP}$, a estimativa do efeito da CGC do genitor D demonstra ocorrer aumento na resistência da planta a cercosporiose em Água Doce $(1,66)$, Iraí de Minas $(0,67)$ e Chapadão do Céu $(0,63)$. Porém este mesmo genitor reduziu o RG em 1.386 e $484 \mathrm{~kg} \mathrm{ha}^{-1}$ respectivamente, em Iraí de Minas e Chapadão do Céu. 
Tabela 6 - Médias do rendimento de grãos $\left(\mathrm{kg} \mathrm{ha}^{-1}\right)$ de cinco genitores e seus híbridos recíprocos, em três locais de cultivo. Lages/SC, 2009

\begin{tabular}{|c|c|c|c|c|c|}
\hline \multicolumn{6}{|c|}{ Híbridos } \\
\hline LOCAIS & $\mathrm{A}$ & $\mathrm{B}$ & $\mathrm{C}$ & $\mathrm{D}$ & $\mathrm{E}$ \\
\hline \multicolumn{6}{|c|}{ Água Doce } \\
\hline $\mathrm{A}$ & - & 12.342 & 10.892 & 12.900 & 10.870 \\
\hline B & 13.264 & - & 12.222 & 11.812 & 11.844 \\
\hline $\mathrm{C}$ & 11.976 & 12.790 & - & 10.612 & 9.732 \\
\hline $\mathrm{D}$ & 13.024 & 12.166 & 10.938 & - & 8.514 \\
\hline $\mathrm{E}$ & 11.030 & 12.776 & 10.486 & 8.092 & - \\
\hline Média & 12.324 & 12.519 & 11.135 & 10.854 & 10.240 \\
\hline Média geral & & & 11.414 & & \\
\hline \multicolumn{6}{|c|}{ Iraí de Minas } \\
\hline A & - & 8.784 & 8.892 & 8.288 & 8.866 \\
\hline B & 10.578 & - & 9.936 & 6.862 & 8.910 \\
\hline $\mathrm{C}$ & 9.014 & 8.792 & - & 7.912 & 7.946 \\
\hline D & 7.356 & 7.698 & 7.046 & - & 6.350 \\
\hline E & 8.510 & 9.192 & 7.150 & 5.672 & - \\
\hline Média & 8.865 & 8.617 & 8.256 & 7.184 & 32.072 \\
\hline Média geral & & & 8.188 & & \\
\hline \multicolumn{6}{|c|}{ Chapadão do Céu } \\
\hline A & - & 8.910 & 8.534 & 7.988 & 8.542 \\
\hline B & 9.546 & - & 9.480 & 9.184 & 7.860 \\
\hline $\mathrm{C}$ & 8.226 & 9.798 & - & 7.916 & 8.216 \\
\hline $\mathrm{D}$ & 8.870 & 8.520 & 7.552 & - & 7.030 \\
\hline $\mathrm{E}$ & 9.204 & 8.516 & 8.058 & 8.036 & - \\
\hline Média & 8.961 & 8.936 & 8.406 & 8.281 & $\overline{7.912}$ \\
\hline Média geral & & & 8.499 & & \\
\hline
\end{tabular}

Tabela 7 - Estimativas dos efeitos de capacidade geral de combinação (CGC), dos cinco genitores, para severidade de cercosporiose (CP) e rendimento de grãos (RG) em kg ha ${ }^{-1}$ para os três locais. Lages/SC, 2009

\begin{tabular}{ccccccc}
\hline & \multicolumn{2}{c}{ Água Doce } & \multicolumn{2}{c}{ Iraí de Minas } & \multicolumn{2}{c}{ Chapadão do Céu } \\
\hline Genitores & CP & RG & CP & RG & CP & RG \\
\hline A & $1,23^{*}$ & $964,20^{*}$ & $0,67^{*}$ & $798,00^{*}$ & $0,76^{*}$ & 304,20 \\
B & $0,29^{*}$ & $1117,20^{*}$ & $0,39^{*}$ & $874,80^{*}$ & $0,48^{*}$ & $637,20^{*}$ \\
C & 0,01 & $-477,60$ & $-0,17$ & 197,40 & $0,20^{*}$ & $-35,40$ \\
D & $-1,66^{*}$ & $-415,20$ & $-0,67^{*}$ & $-1386,00^{*}$ & $-0,63^{*}$ & $483,60^{*}$ \\
E & $-0,12$ & $1194,60^{*}$ & $-0,22$ & $-484,20^{*}$ & $-0,80^{*}$ & $-422,40^{*}$ \\
\hline
\end{tabular}

* significativo a $5 \%$ pelo teste $F$ 
Todavia, o genitor E apresentou redução na severidade da doença de 0,80 somente em Chapadão do Céu, com decréscimos no rendimento de grãos em Água Doce (1.195 kg ha-1), Iraí de Minas (484 kg ha-1) e Chapadão do Céu (422 kg ha-1), (TAB. 7).

Neste estudo, os genitores com maior grau de resistência à cercosporiose ( $\mathrm{D}$ e E), conforme a CGC, foram também os que obtiveram os menores rendimentos de grãos. Resultados similares foram descritos por Buiate et al. (2008), em avaliação de doenças em grãos de diferentes híbridos, onde o híbrido com maior resistência foi o mesmo que obteve os menores rendimentos nos locais avaliados.

Para o sucesso de um programa de melhoramento na cultura do milho devem ser encontrados genitores divergentes e altamente produtivos, associados à resistência aos patógenos que provocam redução no rendimento de grãos.

A análise dialélica permite escolher os híbridos de maior CEC no qual uma das linhagens genitoras apresenta a maior CGC. A estimativa da CEC indica as melhores combinações híbridas a serem utilizadas, porém, não evidenciam se o comportamento do híbrido é em função do genitor fêmea ou macho. Para tal inferência, utilizamse as estimativas dos efeitos recíprocos, que neste caso não foram significativos e ainda avaliam-se os efeitos da CGC dos genitores para a escolha dos melhores híbridos.

Para a variável $\mathrm{CP}$ as melhores combinações híbridas foram $\mathrm{AxEeDxE}$, queaumentaram aresistênciaàcercosporiose em 0,47 e 0,42, respectivamente, em Água Doce. Ainda, os híbridos $\mathrm{AxD}, \mathrm{BxE}$ e $\mathrm{CxE}$, respectivamente, estimaram aumento da severidade da ocorrência da doença em 0,64 , 0,47 e 0,42. Em Chapadão do Céu as melhores combinações híbridas foram $\mathrm{AxB}, \mathrm{DxE}$ e $\mathrm{BxC}$ com respectivas estimativas negativas da CEC (redução da doença) de -0,42, -0,42 e -0,36. No entanto, três híbridos demonstraram aumento no caráter $\mathrm{CP}$ : O híbrido $\mathrm{BxD}$, com 0,47 de acréscimo na severidade da doença, AxC com 0,36 e BxE com 0,31 (TAB. 8).

Para o caráter RG houve diferença significativa entre os híbridos avaliados. Os híbridos AxD e BxE obtiveram, em Água Doce, incremento no rendimento de grãos com estimativas de 1.093 e $1.073 \mathrm{~kg} \mathrm{ha}^{-1}$ respectivamente.

Tabela 8 - Estimativas dos efeitos de capacidade específica de combinação dos vinte híbridos formados para severidade de cercosporiose (CP) e rendimento de grãos (RG) em kg ha ${ }^{-1}$ para os três locais. Lages/SC, 2009

\begin{tabular}{|c|c|c|c|c|c|c|}
\hline \multirow[b]{2}{*}{ Genótipos } & \multicolumn{2}{|c|}{ Água Doce } & \multicolumn{2}{|c|}{ Iraí de Minas } & \multicolumn{2}{|c|}{ Chapadão do Céu } \\
\hline & $\mathrm{CP}$ & $\mathrm{RG}$ & $\mathrm{CP}$ & $\mathrm{RG}$ & $\mathrm{CP}$ & $\mathrm{RG}$ \\
\hline $\mathrm{AxB}$ & $-0,14$ & $-592,80$ & 0,28 & $-178,80$ & $-0,42 *$ & $-211,80$ \\
\hline $\mathrm{AxC}$ & $-0,03$ & $-366,60$ & $-0,17$ & $-230,40$ & $0,36^{*}$ & $-388,20$ \\
\hline $\mathrm{AxD}$ & $0,64 *$ & $1093,20 *$ & 0,00 & 222,60 & 0,03 & 108,60 \\
\hline $\mathrm{AxE}$ & $-0,47^{*}$ & $-133,20$ & $-0,11$ & 186,60 & 0,03 & $491,40^{*}$ \\
\hline $\mathrm{BxA}$ & 0,00 & $-462,00$ & 0,33 & $-895,80^{*}$ & $-0,33$ & $-316,80$ \\
\hline $\mathrm{BxC}$ & $-0,25$ & $-447,60$ & 0,11 & 102,60 & $-0,36^{*}$ & $539,40 *$ \\
\hline $\mathrm{BxD}$ & $-0,08$ & $-33,00$ & $-0,22$ & $-396,60$ & $0,47 *$ & 198,60 \\
\hline $\mathrm{BxE}$ & 0,47 & $1073,40 *$ & $-0,17$ & 472,80 & $0,31^{*}$ & $-526,20 *$ \\
\hline $\mathrm{CxA}$ & $-0,17$ & $-541,80$ & 0,00 & $-61,20$ & 0,17 & 154,20 \\
\hline $\mathrm{CxB}$ & 0,33 & $-1284,0^{*}$ & $-0,33$ & 571,20 & $-0,17$ & $-157,80$ \\
\hline $\mathrm{CxD}$ & $-0,14$ & 347,40 & 0,00 & 480,00 & $-0,08$ & $-246,60$ \\
\hline $\mathrm{CxE}$ & $0,42 *$ & 466,80 & 0,06 & $-352,80$ & 0,08 & 95,40 \\
\hline DxA & 0,17 & $-61,80$ & 0,00 & 466,20 & 0,00 & $-441,00$ \\
\hline $\mathrm{DxB}$ & 0,50 & $-177,0$ & 0,17 & $-418,2$ & 0,17 & 331,8 \\
\hline $\mathrm{DxC}$ & 0,17 & $-163,2$ & 0,17 & 433,2 & 0,00 & 181,8 \\
\hline DxE & $-0,42 *$ & $-60,6$ & 0,22 & $-306,0$ & $-0,42 *$ & $-60,6$ \\
\hline ExA & $-0,17$ & $-79,8$ & 0,00 & 178,2 & 0,17 & $-331,2$ \\
\hline ExB & 0,17 & $-466,2$ & 0,00 & $-141,0$ & $-0,17$ & $-328,2$ \\
\hline $\mathrm{ExC}$ & 0,50 & $-376,8$ & $-0,33$ & 397,8 & 0,00 & 79,2 \\
\hline ExD & 0,00 & 211,2 & 0,33 & 339,0 & 0,00 & $-502,8$ \\
\hline
\end{tabular}

* significativo a $5 \%$ pelo teste $F$ 
Todavia, a CEC estimada para o híbrido $\mathrm{CxB}$ foi de redução no $\mathrm{RG}$ em $1.284 \mathrm{~kg} \mathrm{ha}^{-1}$. Em Chapadão do Céu, o RG foi reduzido em $526 \mathrm{~kg} \mathrm{ha}^{-1}$ para BxE, porém AxE e BxC obtiveram aumento no rendimento de grãos na ordem de 491 e $539 \mathrm{~kg} \mathrm{ha}^{-1}$, respectivamente (TAB. 8).

Para o local Iraí de Minas, não houve diferenças significativas quanto a $\mathrm{CP}$ e RG, exceto para o híbrido BxA que obteve um decréscimo significativo de $896 \mathrm{~kg} \mathrm{ha}^{-1}$ para o caráter rendimento de grãos.

A partir dos resultados, as melhores combinações de híbridos foram AxD e BxE, no local Água Doce, e os híbridos $\mathrm{BxC}$ e $\mathrm{AxE}$, em Chapadão do Céu, pois elevaram o RG, fato esse que mesmo com o aumento da severidade da cercosporiose em Água Doce para os híbridos AxD e BxE deve ser levado em consideração, pois o caráter rendimento de grãos em um programa de melhoramento de milho é fator decisivo para a continuação no programa de pesquisa.

\section{Conclusões}

1. A análise dialélica demonstrou que os efeitos da CGC foram mais importantes que a CEC nesse conjunto de genitores, demonstrando a importância da ação gênica aditiva para os caracteres avaliados;

2. A CGC indicou que os genitores A e B são os mais promissores para o aumento do rendimento de grãos e o genitor D para o aumento da resistência à cercosporiose;

3. A CEC indicou que as melhores combinações híbridas foram $\mathrm{AxD}, \mathrm{BxE}, \mathrm{AxE}$ e BxC, com destaque aos híbridos $\mathrm{AxD}$ e $\mathrm{BxC}$ que estimaram aumento no rendimento de grãos com aumento da resistência a cercosporiose;

4. Os híbridos $\mathrm{AxB}$ e $\mathrm{BxA}$ devem ser novamente avaliados, pois apresentaram maiores médias de rendimento de grãos;

5. O modelo dialélico utilizado é uma metologia viável para utilização em programas de melhoramento, visto que obtiveram-se híbridos promissores a partir deste conjunto de genitores.

\section{Referências}

AGROCERES. Guia agroceres de sanidade. São Paulo: sementes Agroceres, 1996. $72 \mathrm{p}$.

AGUIAR, A. M. et al. Combining ability of inbred lines of maize and stability of their respective single-crosses. Scientia Agricola, v. 60, n. 01, p. 83-89, 2003.
BARBIERI, L. R. et al. Análise dialélica para tolerância ao vírus-do-nanismo-amarelo-da-cevada em cultivares brasileiras de trigo. Pesquisa Agropecuária Brasileira, v. 36, n. 01, p. 131-135, 2001.

BECK, D. L.; VASAL, S. K.; CROSSA, J. Heterosis and combining ability of CIMMYT's tropical early and intermediate maturity maize (Zea mays L.) germoplasm. Maydica, Bergamo, v. 35 , n. 01 , p. $279-285,1990$.

BRITO, A. H. et al. Efeito da cercosporiose no rendimento de híbridos comerciais de milho. Fitopatologia Brasileira, v. 32, n. 06, p. 472-479, 2007.

BRUNELLI, K. R. Cercospora zeae-maydis: esporulação, diversidade morfo-genética e reação de linhagens de milho. 2004. 118f. Dissertação (Doutorado em Agronomia, Área de Concentração: Fitopatologia) - Escola Superior de Agricultura "Luiz de Queiroz", Universidade de São Paulo, Piracicaba.

BUIATE, E. A. S. et al. Reaction of maize hybrid and survey of the major fungi associated to the pathogen complex causing ear rot in Minas Gerais. Horizonte Científico, v. 01, n. 08, p. 1-14, 2008.

CARDOSO, M. J. et al. Estabilidade do rendimento de grãos de variedades de Zea mays $L$. no Meio-Norte brasileiro. Revista Ciência Agronômica, v. 38, n. 01, p. 78-83, 2007.

CROMLEY, J. M. D.; HALLAUER, A. R.; MARTINSON, C. A. Inheritance of gray leaf spot resistance in corn. Journal of the Iowa Academy of Science, v. 109, n. 01, p. 25-29, 2002.

CRUZ C. D.; REGAZZI A. J. Modelos biométricos aplicados ao melhoramento genético. Viçosa: UFV, 1997. 390 p.

DERERA, J. et al. Gene action controlling gray leaf spot resistance in Southern African mayze germplasm. Crop Science, v. 48, n. 01, p. 93-98, 2008.

FERREIRA, P. A. et al. Produção relativa do milho e teores folheares de nitrogênio, fósforo, enxofre e cloro em função da salinidade do solo. Revista Ciência Agronômica, v. 38, n. 01, p. 07-16, 2007.

GAMA, E. E. et al. Heterosis in maize single crosses derived from a yellow Tuxpeño variety in Brazil. Brazilian Journal of Genetics, v. 18, n. 01, p. 81-85, 1995.

GRIFFING, B. Concept of general and specific combining ability in relation to diallel crossing systems. Australian Journal Biology Science. v. 09, n. 01, p. 463-493, 1956.

KOUTSIKA-SOTIRIOU,M.S.;KARAGOUNIS,C.A. Assessment of maize hybrids. Maydica, v. 50, n. 01, p. 63-70, 2005.

MENKIR, A.; AYODELE, M. Genetic analyses of resistance to gray leaf spot of mid altitude maize inbred lines. Crop Science, v. 45 , n. 01 , p. 163-170, 2005.

MIRANDA, J. E. C.; COSTA, C. P.; CRUZ, C. D. Análise dialélica em pimentão. I: capacidade combinatória. Revista Brasileira de Genética, v. 11, n. 02, p. 431-440, 1998.

MONTEZANO,Z.F.;CORAZZAE.J.;MURAOKAT.Variabilidade de nutrientes em plantas de milho cultivado em talhão manejado homogeneamente. Bragantia, v. 67, n. 04, p. 969-976, 2008. 
MUNKVOLT, G. P. et al. Probabilities for profitable fungicide use against gray leaf spot in hybrid maize. Phytopathology, v. 91, n. 05 , p. $477-484,2001$.

PARENTONI, S. N. et al. Avaliação da capacidade combinatória de dez linhagens de milho doce. Horticultura Brasileira, v. 09, n. 02 , p. 71-73, 1991

PEGORARO, D. G. et al. Herança da resistência a mancha foliar de feosféria em milho. Pesquisa Agropecuária Brasileira, v. 37, n. 03, p. 329-336, 2002.

PIO-RIBEIRO, G. et al. Doenças do caupi (Vigna unguiculata). In: KIMATI, H. et al. Manual de fitopatologia: doenças das plantas cultivadas. 4. ed. São Paulo: Agronômica Ceres, 2005. cap.24, p.215-222.

REIS, E. M.; CASA, R. T.; BRESOLIN, A. C. R. Manual de diagnose e controle de doenças do milho. 2. ed. rev. atual. Lages: Graphel, 2004. 144 p.

FUNDAÇÃO ESTADUAL DE PESQUISA AGROPECUÁRIA (FEPAGRO). (50 e 33: 2005: Porto Alegre). Indicações técnicas para cultivo de milho e sorgo no Rio Grande do Sul 2005/2006. In.: REUNIÃO TÉCNICA ANUAL DE PESQUISA DE MILHO E SORGO DO RS, 50. Porto Alegre: FEPAGRO/ Emater-RS/ASCAR, 2005. 155 p.

SILVA, H. P. et al. Capacidade de combinação e heterose para resistência a Puccinia polysora Underw. em milho. Scientia Agricola, v. 58, n. 04, p. 777-783, 2001.

SPRAGUE G. F.; TATUM L. A. General vs. specific combining ability in single crosses of corn. Journal of de American Society of Agronomy, v. 34, n. 10, p. 923-932, 1942.

THOMPSON, D. L. et al. Inheritance of resistance to gray leaf spot in maize. Crop Science, v. 27, n. 02, p. 243-246, 1987.

TROYER, A. F. Background of U.S. hybrid corn. Crop Science, v. 39, n. 03, p. 601-626, 1999.

ULRICH, J. F. et al. Diallel analysis of maize inbreeds for resistance to gray leaf spot. Crop Science, v. 30, n. 06, p. 1198-1200, 1990. 